\title{
Analisis Kebutuhan Air Irigasi Pada Jaringan Sekunder Di Kota Palopo
}

\author{
Kartini Sari ${ }^{1}$, Budiawan Sulaeman ${ }^{2}$ \\ ${ }^{I}$ Dosen Program Studi Teknik Sipil, Universitas Andi Djemma, Palopo \\ ${ }^{2}$ Dosen Program Studi Teknik Informatika, Universitas Andi Djemma, Palopo \\ E-mail: ${ }^{1}$ tin.sary@yahoo.com, ${ }^{2}$ budiawan.unanda@yahoo.com
}

\begin{abstract}
Abstrak
Tujuan khusus penelitian ini untuk menganalisis banyaknya debit air dan efesiensi kebutuhan air pada jaringan irigasi sekunder di Kelurahan Mawa Kecamatan Sendana Kota Palopo. Urgensi penelitian ini, untuk mengetahui efisiensi irigasi dalam melakukan pengukuran dan pengaturan yang tepat sasaran, volume irigasi untuk memenuhi kebutuhan pertumbuhan tanaman. Metode

Kata kunci yang digunakan dalam pengukuran debit adalah metode pelampung (apung) dengan Cara mengambil beberapa titik koordinat geografis irigasi untuk pengambilan data, sehingga Air; Irigasi; memberikan data yang akurat dalam pengembangan irigasi di Kelurahan Mawa Kecamatan Sekunder; Mawa; Sendana kedepan.Hasil penelitian; (1). Jumlah air yang masuk di saluran sekunder hulu sebesar Sendana. $\quad 0.3580 \mathrm{~m} 3 /$ det., dan tiba di titik akhir penelitian sangat kurang yaitu sebesar $0.0985 \mathrm{~m} 3 / \mathrm{det}$, dan jika dihitung secara keseluruhan dapat diketahui total jumlah debit airyang masuk pada jaringan irigasi sekunder Mawa yaitu 2,29170436 m3/det. atau setara dengan 2.291.704,36 liter/ha. (2). Efesiensi penggunaan air irigasi jaringan sekunder Mawa sebesar 36\%, dan kehilangan air disepanjang saluransebesar $64 \%$, hal ini menandakan bahwa saluran sekunder Mawa masih belum mencapai standar efesiensi yang diharuskan oleh direktorat jendral pengairan, departemen pekerjaan umum yang dipersyaratkan dalam standar perencanaan irigasi KP-01.
\end{abstract}

\begin{tabular}{|c|c|}
\hline & Abstract \\
\hline $\begin{array}{l}\text { Keywords } \\
\text { Water; } \\
\text { Irrigation; } \\
\text { Secondary; } \\
\text { Mawa; Sendana. }\end{array}$ & $\begin{array}{l}\text { The specific purpose of this research is to analyze the amount of water discharge and the efficiency } \\
\text { of water needs in secondary irrigation networks in Mawa Village, Sendana District, Palopo City. } \\
\text { The urgency of this research is to determine the efficiency of irrigation in measuring and setting } \\
\text { the right target of irrigation volume to meet the needs of plant growth. The method used in } \\
\text { measuring discharge is the buoy method by taking several geographic coordinates of irrigation as } \\
\text { data collection, so as to provide accurate data in the development of irrigation in Mawa Village, } \\
\text { Sendana District in the future. The results: (1) The amount of water that enters the upstream } \\
\text { secondary channel is } 0.3580 \mathrm{~m} 3 / \mathrm{s} \text { and arrives at the endpoint of the study with a very low amount } \\
\text { of water, namely } 0.0985 \mathrm{~m} 3 / \mathrm{s} \text {, and if it is calculated as a whole it can be seen the total amount of } \\
\text { water discharge. which is included in the Mawa secondary irrigation network, namely } 2.29170436 \\
\text { m3/s or equivalent to } 2,291,704.36 \text { liters/ha. (2) The efficiency of the use of Mawa's secondary } \\
\text { network irrigation water is } 36 \% \text {, and the water loss along the canal is } 64 \% \text {, this indicates that the } \\
\text { Mawa secondary channel still has not reached the efficiency standard required by the Directorate } \\
\text { General of Irrigation, under the Ministry of Public Works which is required in irrigation planning } \\
\text { standards KP-01. }\end{array}$ \\
\hline
\end{tabular}

\section{PENDAHULUAN}

Air adalah sumber daya alam yang sangat penting untuk kelangsungan hidup semua makhluk hidup. Pengelolahan air yang salah dapat menjadi bencana bagi kehidupan kita (Sari, 2018). Melalui siklus hidrologi yang berlangsung terus-menerus. Ketersediaan air bersifat terbatas, sedangkan kebutuhan air cenderung mengalami peningkatan baik dari segi kuantitas, kualitas dan jenis kebutuhannya (Turu, 2016). Jika air yang digunakan belum memenuhi standar kualitas air bersih, akibatnya akan menimbulkan masalah lain yang dapat menimbulkan kerugian bagi penggunanya (Suppa, 2018). Air merupakan unsur yang sangat berperan dalam kehidupan khususnya untuk kehidupan manusia (Sari, 2019). Air juga merupakan kebutuhan pokok hidup manusia baik untuk makan, minum, mandi, dan mencuci, bahkan dapat digunakan sebagai media transportasi (Fisu, 2016). Dalam memenuhi kebutuhan air khususnya untuk kebutuhan air di persawahan maka perlu didirikan sistem irigasi dan bangunan bendung. Kebutuhan air di persawahan ini kemudian disebut dengan kebutuhan air irigasi. Untuk irigasi, pengertiannya adalah usaha penyediaan, 
pengaturan dan pembuangan air irigasi untuk menunjang pertanian yang jenisnya meliputi irigasi permukaan, irigasi rawa, irigasi air bawah tanah, irigasi pompa, dan irigasi tambak. Tujuan irigasi adalah untuk memanfaatkan air irigasi yang tersedia secara benar yakni seefisien dan seefektif mungkin agar produktivitas pertanian dapat meningkat sesuai yang diharapkan.

Air irigasi di Indonesia umumnya bersumber dari sungai, waduk, air tanah dan sistem pasang surut. Salah satu usaha peningkatan produksi pangan khususnya padi adalah tersedianya air irigasi di sawah sawah sesuai dengan kebutuhan. Kebutuhan air yang diperlukan pada areal irigasi besarnya bervariasi sesuai keadaan. Di dalam proyek-proyek pembagian air tidak diukur atau diatur, air lebih akan mengalir ke selokan pembuang. Para pemakai air tergabung dalam suatu kelompok yang Sama dan tidak diperlukan keterlibatan pemerintah di dalam organisasi jaringan irigasi semacam ini. Persediaan air biasanya melimpah dan kemiringan berkisar antara sedang sampai curam. Oleh karena itu hampir-hampir tidak diperlukan teknik yang sulit untuk pembagian air (Harianto, 2018).

Jika ketersediaan tidak dapat memenuhi kebutuhan maka dapat dicari solusinya bagaimana kebutuhan tersebut tetap harus dipenuhi. Kebutuhan air irigasi secara keseluruhan perlu diketahui karena merupakan salah satu tahap penting yang diperlukan dalam perencanaan dan pengelolaan sistem irigasi. Dari latar belakang diatas, penulis Akan menganalisis kebutuhan air irigasi pada jaringan sekunder di Kota Palopo. Salah satu jaringan irigasi sekunder terdapat di Kelurahan Mawa Kecamatan Sendana.

Tujuan khusus penelitian ini untuk menganalisis banyaknya debit air dan efesiensi kebutuhan air pada jaringan irigasi sekunder di Kelurahan Mawa Kecamatan Sendana Kota Palopo.

Urgensi penelitian ini, untuk mengetahui efisiensi irigasi dalam melakukan pengukuran dan pengaturan yang tepat sasaran, volume irigasi untuk memenuhi kebutuhan pertumbuhan tanaman. Metode yang digunakan dalam pengukuran debit adalah metode pelampung (apung) dengan Cara mengambil beberapa titik koordinat geografis irigasi untuk pengambilan data, sehingga memberikan data yang akurat dalam pengembangan irigasi di Kelurahan Mawa Kecamatan Sendana kedepan.

\section{METODELOGI}

Irigasi adalah usaha penyediaan, pengaturan, dan pembuangan air irigasi untuk menunjang pertanian yang jenisnya meliputi irigasi permukaan, irigasi rawa, irigasi air bawah tanah, irigasi pompa, dan irigasi tambak. Sistem irigasi meliputi prasarana irigasi, air irigasi, manajemen irigasi, kelembagaan pengelolaan irigasi, dan sumber daya manusia. Jaringan irigasi adalah saluran, bangunan, dan bangunan pelengkapnya yang merupakan satu kesatuan yang diperlukan untuk penyediaan, pembagian, pemberian, penggunaan, dan pembuangan air irigasi. Saluran irigasi air tanah adalah bagian dari jaringan irigasi air tanah yang dimulai setelah bangunan pompa sampai lahan yang diairi. Masyarakat petani adalah kelompok masyarakat yang bergerak dalam bidang pertanian, baik yang telah tergabung dalam organisasi perkumpulan petani pemakai air maupun petani lainnya yang belum tergabung dalam organisasi perkumpulan petani pemakai air. (Kastapoetra, 2010)

\subsection{Fungsi Irigasi}

Irigasi tidak hanya digunakan untuk mendistribusikan air, ada juga beberapa fungsi irigasi antara lain: (a) Membasahi tanah, hal ini merupakan salah satu tujuan terpenting karena tumbuhan banyak memerlukan air selama masa tumbuhnya. Pembasahan tanah ini bertujuan untuk memenuhi kekurangan air apabila hanya ada sedikit air hujan. (b) Merabuk tanah atau membasahi tanah dengan air sungai yang banyak mengandung mineral. (c) Mengatur suhu tanah agar tanaman dapat tumbuh dengan baik dengan suhu yang optimal. Air irigasi dapat membantu tanaman untuk mencapai suhu yang optimal tersebut. (d) Membersihkan tanah dengan tujuan untuk menghilangkan Hama tanaman seperti ular, tikus, serangga, dan lain-lain. Selain itu dapat juga membuang zat-zat yang tidak dibutuhkan oleh tanaman ke saluran pembuang. (e) Memperbesar ketersediaan air tanah karena muka air tanah naik apabila digenangi air irigasi yang meresap. Dengan naiknya muka air tanah, maka debit sungai pada musim kemarau Akan naik. (f) Mengurangi berlimpahnya air hujan di daerah-daerah yang kelebihan air dengan maksud mencegah peluapan air dan kerusakan tanah.

Dengan demikian pengaturan irigasi Akan menjangkau beberapa teknis sebagai berikut; (a) Pengembangan sumber air dan penyediaan air bagi keperluan usaha tani. (b) Penyaluran air irigasi dari sumbernya ke daerah/lahan usaha tani. (c) Pembagian dan pemberian air di daerah/lahan usaha tani (d) Pengaliran dan pembuangan air yang melimpah dari daerah pertanian. Keseluruhan di atas mempunyai tujuan utama yaitu membasahi tanah guna menciptakan keadaan lembab di sekitar daerah perakaran agar tanaman tumbuh dengan baik. (Asdak, 2010) 


\subsection{Debit Air}

Adalah suatu koefisien yang menyatakan banyaknya air yang mengalir dari suatu sumber persatu-satuan waktu, biasanya diukur dalam satuan liter perdetik. Pengukuran debit dapat dilakukan dengan berbagai Cara antara lain.

a) Pengukuran Debit Secara Langsung

Besarnya aliran tiap waktu disebut dengan debit, Akan tergantung pada luas tampang aliran dan kecepatan aliran rata-rata. Pendekatan nilai debit dapat dilakukan dengan mengukur tampang aliran dan mengukur kecepatan aliran tersebut. Cara ini merupakan prosedur umum dalam pengukuran debit secara langsung. Pengukuran luas tampang aliran dilakukan dengan mengukur tinggi muka air dan lebar dasar alur sungai. Pengukuran debit melalui ambang dapat dilakukan pada aliran yang melalui ambang yang prinsip hitungannya adalah dengan menggunakan rumus:

$$
Q=C \times B \times H^{m} \text {. }
$$

Dengan:

$$
\begin{aligned}
& \text { Q }=\text { Debit Aliran Melalui Ambang }\left(\mathrm{m}^{3} / \mathrm{det}\right) \\
& \mathrm{B}=\text { Lebar Ambang }(\mathrm{m}) \\
& \mathrm{H} \quad=\text { Tinggi Aliran diatas Ambang }(\mathrm{m}) \\
& \mathrm{C}, \mathrm{m}=\text { Konstanta yang tergantung pada bentuk ambang. }
\end{aligned}
$$

\section{b) Pengukuran Debit Secara Tidak Langsung}

Pengukuran debit secara tidak langsung sering sekali diperlukan pengukuran dengan Cara ini dapat dilaksanakan apabila pangukuran secara langsung sulit dilakukan bagi petugas pengatur air. Cara ini masih dapat digunakan untuk memperoleh gambaran kasar tentang kecepatan aliran dan karena kondisi saluran yang sangat sulit diukur. Dalam pengukuran debit air secara tidak langsung, yang sangat perlu diperhatikan adalah kecepatan aliran dan luas penampang aliran. Rumus untuk menghitung debit air adalah sebagai berikut:

$$
\mathrm{Q}=\mathrm{A} \times \mathrm{V} \text {. }
$$

Dimana:

$$
\begin{aligned}
\mathrm{Q} & =\text { Debit air }\left(\mathrm{m}^{3} / \text { det }\right) \\
\mathrm{V} & =\text { Kecepatan aliran }(\mathrm{m} / \mathrm{det}) \\
\mathrm{A} & =\text { Luas penampang aliran }\left(\mathrm{m}^{2}\right)
\end{aligned}
$$

Luas Penampang Basah, sebagai beikut;

$$
\mathrm{A}=\{(\mathrm{a}+\mathrm{B}) / 2\} \times \mathrm{h}
$$

Dimana:

$$
\begin{aligned}
\mathrm{A} & =\text { Luas penampang Basah }\left(\mathrm{m}^{2}\right) \\
\mathrm{A} & =\text { Lebar Permukaan air }(\mathrm{m}) \\
\mathrm{B} & =\text { Lebar bawah saluran }(\mathrm{m}) \\
\mathrm{H} & =\text { Tinggi muka air }(\mathrm{m})
\end{aligned}
$$

Untuk mengukur kecepatan aliran dapat menggunakan metode pelampung atau menggunakan current meter. Alat pelampung diapungkan sampai jarak tertentu dan waktunya dicatat dengan stopwatch. Pengukuran dilakukan lebih dari satu kali untuk mendapatkan kecepatan alir rata-rata. [3]

c) Perhitungan Efesiensi Kebutuhan Air

Efisiensi irigasi adalah melakukan pengukuran dan pengaturan yang tepat sasaran dan tepat volume untuk memenuhi kebutuhan pertumbuhan tanaman. Untuk mencapai efesien tersebut maka perlu diketahui kebutuhan air irigasi lahan persawahan. Rumus efisiensi penyaluran air dinyatakan sebagai berikut :

$$
\mathrm{Ec}=\frac{W f}{W r} \times 100 \%
$$

Dimana : $\quad E c=$ Efisiensi penyaluran air pengairan

$\mathrm{Wf}=$ Jumlah air yang sampai di areal persawahan

$\mathrm{Wr}=$ Jumlah air yang diambil dari pintu air 
Kebutuhan Air Irigasi Lahan Persawahan,

Kebutuhan air irigasi untuk lahan persawahan efektifnya sampai panen hanya \pm 30 hari, ini dapat dihitung dengan mengabaikan jenis- jenis tanah pada lahan persawahan. Berdasarkan dari angka kooefisien dari Irrigation Sub Sector Project (ISSP) ada faktor kooefisien yang dapat digunakan sesuai fase-fase tertentu yaitu 1,25 liter/detik/ha, 0,85 liter/detik/ha, dan 0,425 liter/detik/ha.

\subsection{Lokasi dan Waktu}

Penelitian ini dilaksanakan di Kelurahan Mawa Kecamatan Sendana Kota Palopo, Provinsi Sulawesi Selatan, berfokus pada dampak (impact), lembaga pemerintah yang berkelanjutan (sustainability), kerangka institusional dan proses pembuatan, efisiensi dan informasi. Dalam penelitian ini membutuhkan waktu selama \pm 6 bulan. (Mei s/d OKtober 2020).

\subsection{Pendekatan Penelitian}

Menggunakan pendekatan kualitatif dimana dalam penelitian ini yang dilakukan bersifat deskriptif. Artinya penulis menggunakan FGD, wawancara, catatan laporan, dan observasi langsung ke lapangan untuk mnggambarkan fenomena yang berhubungan dengan Eksisting Saluran Irigasi Kelurahan Mawa Kecmatan Sendana Kota Palopo

\subsection{Tipe Penelitian}

Tipe penelitian yang digunakan adalah tipe penelitian deskriptif. Penelitian deskriptif (penggambaran) ini merupakan suatu penelitian yang akan memprediksikan Eksisting Saluran Irigasi Kelurahan Mawa Kecmatan Sendana Kota Palopo. Hal ini dilakukan untuk mendeskripsikan, mencatat, menganalisa, dan menginterpretasikan kondisi yang terjadi saat ini.

\subsection{Rancangan Penelitian}

Menggunakan penelitian kualitatif adalah kata-kata dan tindakan, selebihnya adalah data tambahan seperti dokumen pendukung. Data hasil penelitian didapatkan melalui dua sumber yaitu: (1) Data primer Kondisi Eksisting Saluran Irigasi dan (2) Data sekunder, Luasan Areal Persawahan Kelurahan Mawa Kecamatan Sendana Kota Palopo, Tahun 2020.

\subsection{Analisis Data}

Kebutuhan air Irigasi pada Jaringan Sekunder di Kota Palopo. Berikut diagram alir proses pengumpulan dan analisis data.

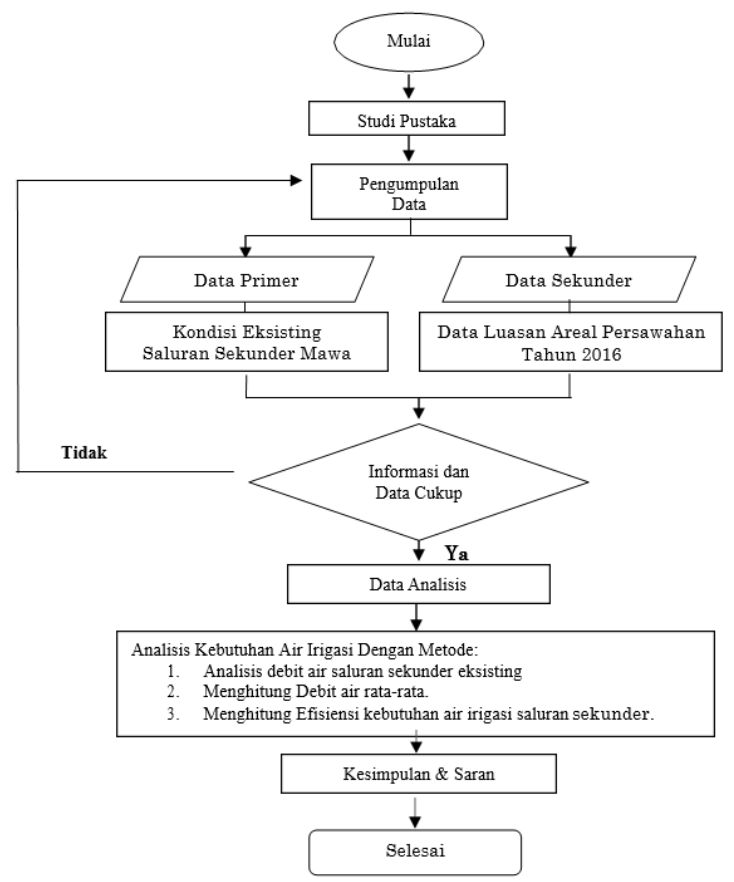

Gambar 1. Diagram alir proses pengumpulan dan analisis data 


\section{HASIL DAN PEMBAHASAN}

\subsection{Secara Geografis}

Kota Palopo Kurang Lebih $375 \mathrm{Km}$ dari Kota Makassar ke arah Utara dengan posisi antara 120 derajat 03 sampai dengan 120 derajat 17,3 Bujur Timur dan 2 derajat 53,13 sampai dengan 3 derajat 4 Lintang Selatan, pada ketinggian 0 sampai 300 meter di atas permukaan laut. Kota palopo sebelah utara berbatasan dengan Kab.Luwu, sebelah selatan berbatasan dengan Kab.luwu, sebelah timur berbatasan dengan Teluk Bone, dan sebelah barat berbatasan dengan Kab.Luwu dan Kab.Toraja.

\subsection{Kondisi Jaringan Irigasi Eksisting Sekunder Mawa}

Inventasrisasi jaringan irigasi eksisting diperlukan untuk mengetahui kondisi kapasitas dan permasalahan pada saluran termasuk dampak akibat permasalahan tersebut. Data - data mengenai jaringan irigasi, kodisi saluran, permasalahan terhadap kawasan penelitian. Data saluran irigasi diperoleh dengan cara observasi dan pengukuran langsung dilapangan dan hasilnya disajikan sebagai berikut: (1) Panjang saluaran sekunder eksisting mawa adalah 600 meter. (2) Ukuran penampang melintang saluaran sekunder eksisting dapat dilihat pada. Gambar dibawah;

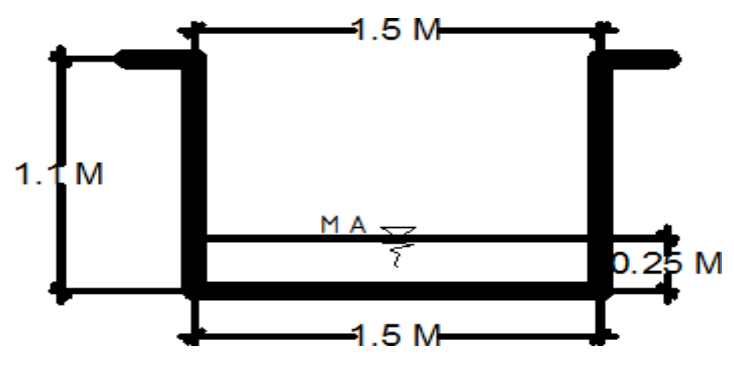

Gambar 2. Dimensi Saluran Sekunder Eksisting.

\subsection{Kondisi Eksisting Saluran Sekunder Mawa}

Cukup buruk karena terjadinya kerusakan pada struktur bangunan irigasi sehingga pendistribusian air pada saluran tersebut tidak mengalir sebagai mana mestinya dan juga dapat dilihat pada gambar dibawah terdapat sedimen, dan eksploitasi disepanjang saluran.

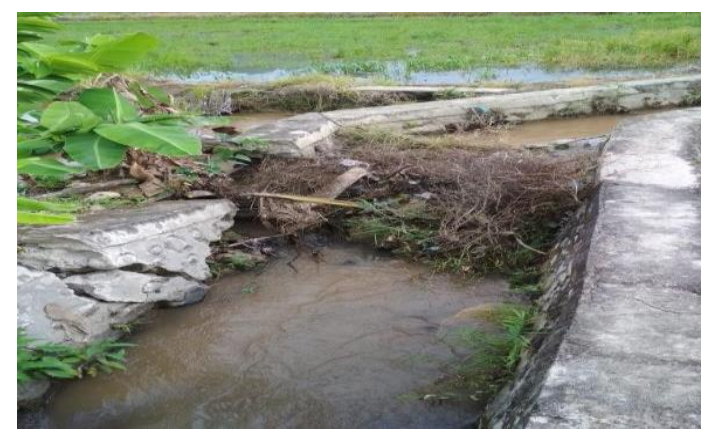

Gambar 3. Kerusakan pada struktur saluran irigasi sekunder (Koordinat : E.120¹1'16.30" S. $\left.3^{\circ} 1^{\prime} 32.50^{\prime \prime}\right)$

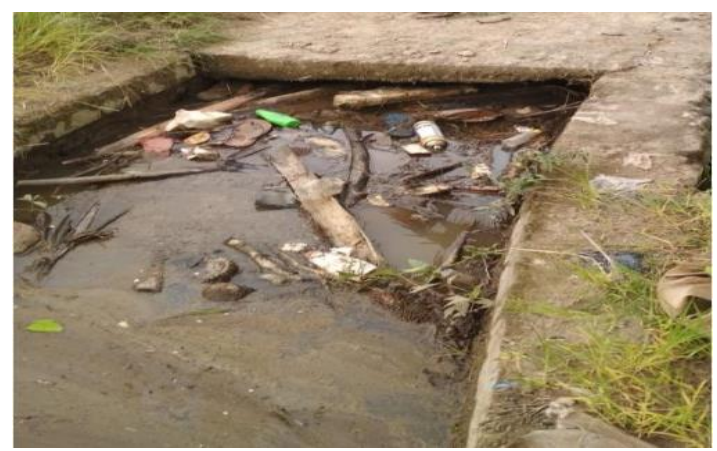

Gambar 4. Sedimen pada saluran sekunder (Koordinat : E $120^{\circ} 11^{\prime} 19.40^{\prime \prime}$ S. $\left.3^{\circ} 1^{\prime} 31.14 "\right)$ 


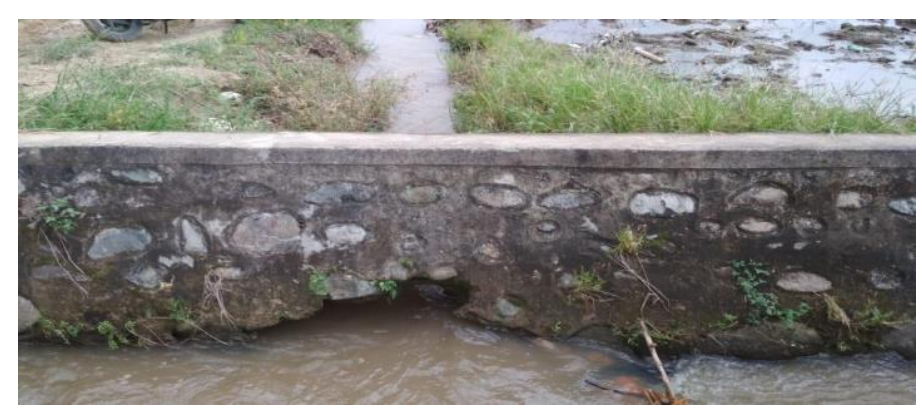

Gambar 5. Eksploitasi disepanjang saluran eksisting (Koordinat : E $120^{\circ} 11^{\prime 23.67 " ~ S ~} 3^{\circ} 11^{\prime} 31.46^{\prime \prime}$ )

\section{Detail Saluran Sekunder P1 - P12, 600 Meter}

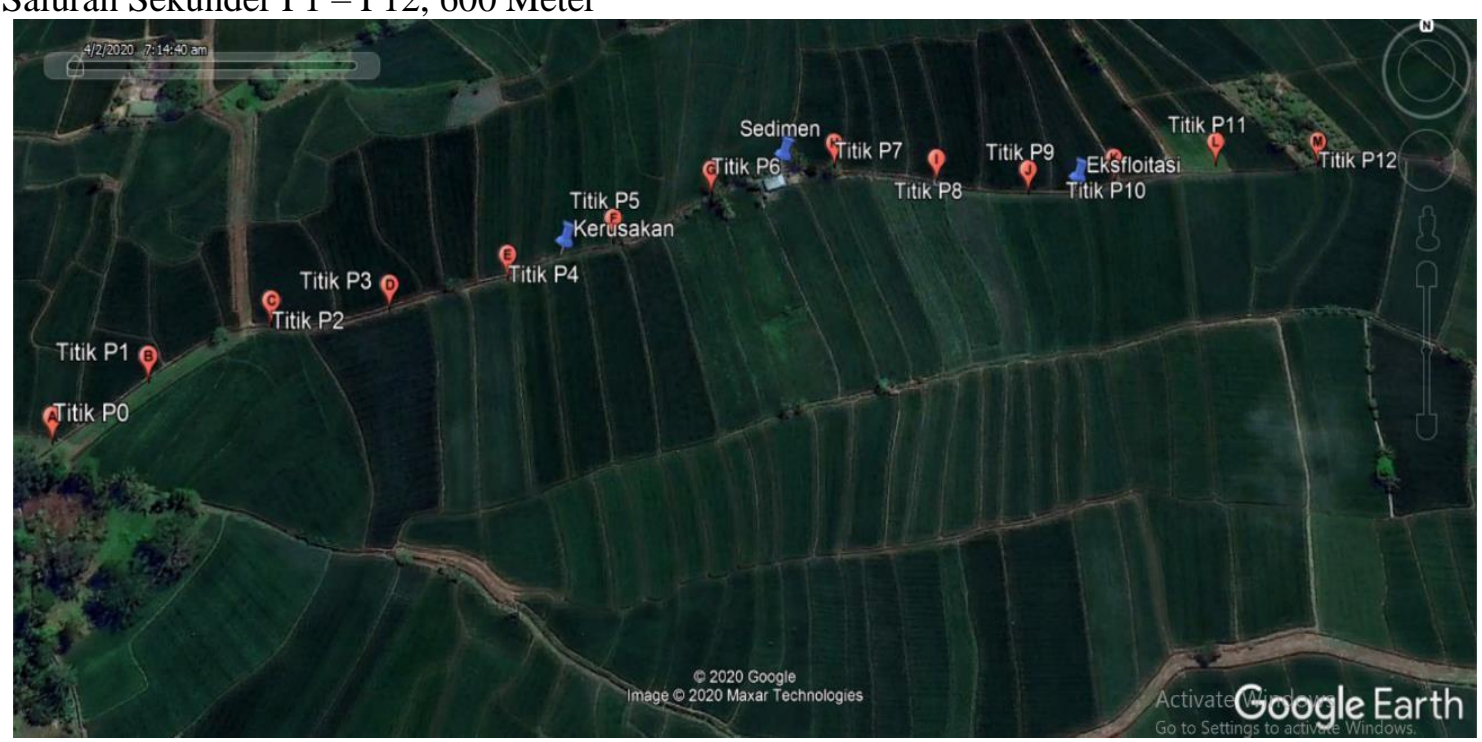

Gambar 6. Gambar saluran Sekunder P0 0+000 - P12 0+600

\subsection{Perhitungan Debit Saluran Sekunder Eksisting}

Analisa debit air pada saluran dilakukan untuk mendapatkan berapa banyak total debit air yang masuk pada jaringan sekunder untuk memenuhi kebutuhan air berdasarkan luas areal yang ada, yang nantinya Akan dibandingkan dengan kondisi fisik yang didaptkan dilapangan. Sehingga dapat diketahui apakah debit air yang masuk pada saluran sekunder tercukupi untuk mecapai efisiensi penggunaanair lahan persawahan. Dalam perhitungan debit air saluran eksisting P0 sampai P12. Menggunakan persamaan 2.

\subsection{Saluran sekunder eksisting P0}

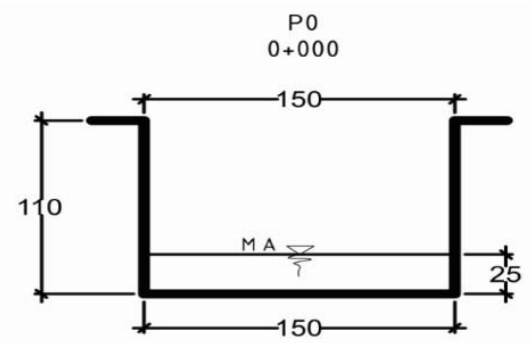

Gambar 7. Dimensi Saluran Eksisting P0

a) Luas Penampang basah saluran $\mathrm{A}=$

$$
\begin{aligned}
& \{(\mathrm{a}+\mathrm{B}) / 2\} \times \mathrm{h} \\
& \quad=(1.5+1.5) / 2 \times 0.25 \\
& \quad=0.375 \mathrm{~m}^{2}
\end{aligned}
$$

b) Debit Saluran Q = A . V 


$$
\begin{aligned}
& =0.375 \mathrm{~m}^{2} \times 0.955 \mathrm{~m} / \mathrm{det} \\
& =0.3850 \mathrm{~m}^{3} / \mathrm{det}
\end{aligned}
$$

\begin{tabular}{|c|c|c|c|c|c|c|c|c|}
\hline \multirow{2}{*}{$\begin{array}{c}\text { P0 } \\
\text { Titik Awal (Hulu) } \\
\text { Sekunder } \\
\end{array}$} & \multicolumn{8}{|c|}{ Titik Koordinat Geografis } \\
\hline & \multicolumn{4}{|c|}{ E 120 ${ }^{\circ} 11^{\prime} 9.88^{\prime \prime}$} & \multicolumn{4}{|c|}{$\mathrm{S} \mathrm{3}^{\circ}$ 1'35.23" $^{\prime \prime}$} \\
\hline \multirow[t]{2}{*}{ No. Percobaan } & \multicolumn{3}{|c|}{$\mathbf{A}$} & \multicolumn{2}{|r|}{$\mathbf{V}$} & \multicolumn{3}{|c|}{$\mathbf{Q}$} \\
\hline & B & $\mathbf{a}$ & $\mathbf{h}$ & $\mathbf{S}$ & $\mathbf{t}$ & $\mathbf{A}$ & & \\
\hline 1 & \multirow{4}{*}{1.5} & \multirow{4}{*}{1.5} & \multirow{4}{*}{0.25} & \multirow{4}{*}{50} & 52.33 & \multirow{4}{*}{0.375} & \multirow{4}{*}{\multicolumn{2}{|c|}{0.955}} \\
\hline 2 & & & & & 52.48 & & & \\
\hline 3 & & & & & 52.32 & & & \\
\hline Rata - Rata & & & & & 52.377 & & & \\
\hline Hasil & $A=$ & & 375 & $\mathrm{~V}=$ & 0.955 & $\mathrm{Q}=$ & 0.3580 & $\mathrm{~m}^{3} /$ det \\
\hline
\end{tabular}

Tabel 1. Data Saluran Sekunder Eksisting P0 di Kel. Mawa Kec. Sendana

Sumber: Data Primer 2020

Tabel 2. Rekap. data Saluran Sekunder Eksisting di Kel. Mawa Kec. Sendana.

\begin{tabular}{|c|l|c|c|c|}
\hline No & \multicolumn{1}{|c|}{ Nama Titik Percobaan } & A & V & Q \\
\hline 1 & P0 Titik Awal (Hulu) Sekunder & 0.375 & 0.955 & 0.3580 \\
\hline 2 & P1 Saluran Sekunder & 0.225 & 1.255 & 0.2825 \\
\hline 3 & P2 Saluran Sekunder & 0.390 & 1.176 & 0.4586 \\
\hline 4 & P3 Saluran Sekunder & 0.450 & 1.124 & 0.5060 \\
\hline 5 & P4 Saluran Sekunder & 0.495 & 0.972 & 0.4812 \\
\hline 6 & P5 Saluran Sekunder & 0.267 & 0.701 & 0.1875 \\
\hline 7 & P6 Saluran Sekunder & 0.523 & 0.552 & 0.2887 \\
\hline 8 & P7 Saluran Sekunder & 0.208 & 0.255 & 0.0530 \\
\hline 9 & P8 Saluran Sekunder & 0.092 & 0.465 & 0.0428 \\
\hline 10 & P9 Saluran Sekunder & 0.392 & 0.684 & 0.2680 \\
\hline 11 & P10 Saluran Sekunder & 0.258 & 0.357 & 0.0919 \\
\hline 12 & P11 Saluran Sekunder & 0.188 & 0.301 & 0.0565 \\
\hline 13 & P12 Saluran Sekunder & 0.329 & 0.299 & 0.0984 \\
\hline 14 & \multicolumn{1}{|c|}{ Rata - rata } & $\mathbf{0 . 3 2 2}$ & $\mathbf{0 . 7 0 0}$ & $\mathbf{0 . 2 4 4}$ \\
\hline
\end{tabular}

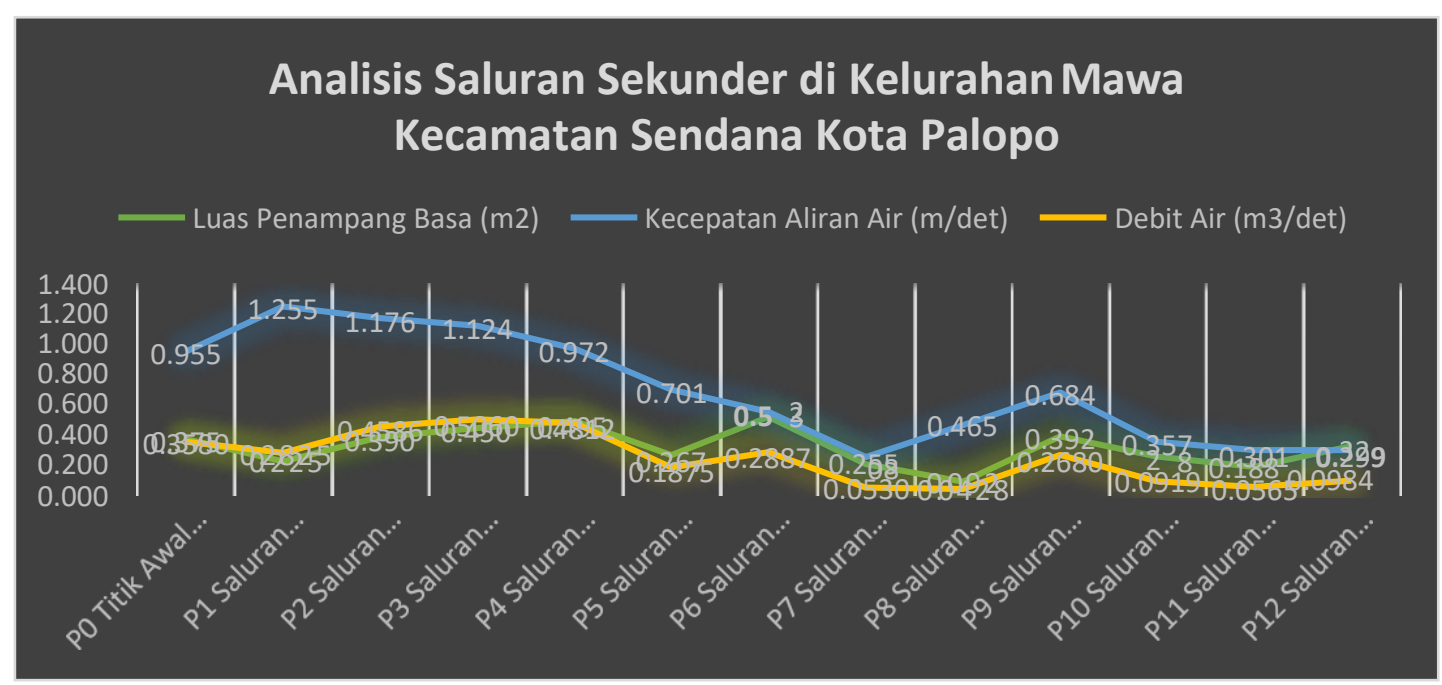

Gambar 8. Analisis Saluran Sekunder 


\subsection{Perhitungan Efesiensi Kebutuhan Air Sekunder Mawa}

Efisiensi irigasi adalah melakukan pengukuran dan pengaturan yang tepat sasaran dan tepat volume untuk memenuhi kebutuhan pertumbuhan tanaman. Untuk mencapai efesien tersebut maka perlu diketahui kebutuhan air irigasi lahan persawahan. Rumus efisiensi (Persamaan 4) penyaluran air. Adapun kebutuhan air sawah yang dijadikan acuan ada 2 metode yaitu : Kebutuhan Air Irigasi dengan Cara Biasa dan Kebutuhan Air Irigasi Pada Lahan Persawahan Berdasarkan System of Rice Intensification (SRI). (1) Kebutuhan Air Irigasi berdasarkan standar perencanaan irigasi KP-01sebanyak 6.912.000 liter/ha. (2) Kebutuhan Air Irigasi Pada Lahan Persawahan Berdasarkan System of Rice Intensification (SRI). Sebanyak 583.200 liter/ha (Sumber : Dirktorat Jenderal Pengairan, 1986).

\subsection{Perhitungan efisiensi}

kebutuhan air menggunakan acuan kebutuhan air irigasi dengan cara biasa berdasarkan standar perencanaan KP-01 dengan cara sebagai berikut :

Luas Areal Persawahan ( F $)=65 \mathrm{Ha}=650.000 \mathrm{~m}^{2}$

Total Kebutuhan Air $(\mathrm{M})=6.912 .000$ liter $/ \mathrm{ha}=6.912 \mathrm{~m}^{3} / \mathrm{ha}$

Jumlah air yang sampai di areal persawahan (Wf ) $=0.59 .904 \mathrm{~m}^{3}$

Jumlah air yang diambil dari pintu air $(\mathrm{Wr})=0.3580 \mathrm{~m}^{3} / \mathrm{ha}$

Diketahui;

$$
\begin{aligned}
& \mathrm{F} \quad \text { : Luas Areal Persawahan }=65 \mathrm{Ha} \\
& \text { M : Total Kebutuhan Air } \quad=6.912 .000 \mathrm{Ltr} / \mathrm{Ha} \\
& =650.000 \mathrm{~m}^{2} \\
& =6.912 \mathrm{~m}^{3} / \mathrm{ha} \\
& \mathrm{F} \times \mathrm{M}=\mathrm{Wf} \\
& =650.000 \mathrm{~m}^{2} \times 6.912 \mathrm{~m}^{3} / \mathrm{ha} \\
& =4492,8 \mathrm{~m}^{3} \\
& \mathrm{Wf} / 75 \text { Hari }=4492,8 \mathrm{~m}^{3} / 75 \\
& =59,904 \mathrm{~m}^{3} \\
& \text { Ec } \quad=\frac{W f}{W r} \times 100 \%
\end{aligned}
$$

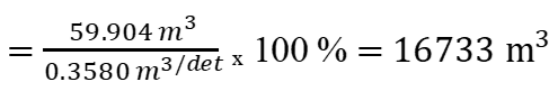

$$
\begin{aligned}
& =\frac{59.904 \mathrm{~m}^{3}}{016733 \mathrm{~m}^{3}} \times 100 \%=0.36 \\
& =0.36 \times 100 \% \quad=36 \%
\end{aligned}
$$

Pembahasan, Jaringan sekunder Mawa mempunyai luas potensial areal persawahan 65 ha, hingga saat ini masih memilih tanam padi sebagai komoditas unggulan. Kebutuhan air irigasi untuk lahan persawahan efektifnya sampai panen hanya \pm 30 hari, ini dapat dihitung dengan berdasarkan dari angka kooefisien dari Irrigation Sub Sector Project (ISSP) ada faktor kooefisien yang dapat digunakan sesuai fase-fase tertentu yaitu 1,25 liter/detik/ha, 0,85 liter/detik/ha dan 0,425 liter/detik/ha. Berdasakan hasil survey yang dilakukan langsung ke lokasi. Kondisi saluran sekunder yang ada, tidak memadai lagi untuk mengalirkan debit air. Hal ini disebabkan oleh banyaknya sadimentasi dan kegiatan eksploitasi pada saluran, yang mengakibatkan terjadinya kerusakan pada sebagian struktur bangunan saluran. Sehingga debit air yang masuk tidak maksimal lagi.

Untuk menganalisis saluran irgasi sekunder Mawa di Kecamatan Sendana Kelurahan Peta Kota Palopo ini dilakukan pengukuran saluran sekunder eksisting dan dibagi menjadi 12 ruas yang memiliki dimensi yang berbeda dengan jarak tiap ruas yang sama. Berdasarkan hasil analisa data debit air yang masuk pada sekunder hulu $0.3580 \mathrm{~m}^{3} /$ det dan tiba di titik akhir penelitian $0.0985 \mathrm{~m}^{3} / \mathrm{det}$, dibandingkan dengan hasil perhitungan rata - rata debit titik awal sampai akhir didapat 2,391704 $\mathrm{m}^{3} / \mathrm{det}$ setara dengan 2.391 .704 liter/ha, dilihat dari tabel kebutuhan air irigasi berdasarkan standar perencanaan KP-01. Jaringan sekunder mawa dianggap belum maksimal mengalirkan debit air sesuai dengan kebutuhan air tanaman dan hasil perhitungan efisiensi 
kebutuhan air yaitu 36\%. Total kehilangan air disepanjang saluran 64\% Sehingga berdasarkan hasil tersebut dinyatakan, dianggap belum mencapai standar Ec yang diharuskan dalam Direktorat Jendral Pengairan dalam standar perencanaan KP-01.

\section{PENUTUP}

\subsection{Kesimpulan}

Berdasarkan analisis dan pembahasan yang telah dilakukan maka dapat diambil kesimpulan sebgai berikut: (1). Dari hasil penelitian di lapangan jumlah air yang masuk di saluran sekunder hulu sebesar $0.3580 \mathrm{~m}^{3} /$ det dan tiba di titik akhir penelitian sangat kurang yaitu sebesar $0.0985 \mathrm{~m}^{3} /$ det. dan jika dihitung secara keseluruhan dapat diketahui total jumlah debit air yang masuk pada jaringan irigasi sekunder Mawa yaitu $2.19874 \mathrm{~m}^{3} /$ det. atau setara dengan 2.198 .74 liter/ha. (2). Dari hasil analisis diperoleh efesiensi penggunaan air irigasijaringan sekunder Mawa sebesar 36\%, dan kehilangan air disepanjang saluransebesar $64 \%$, hal ini menandakan bahwa saluran sekunder Mawa masihbelum mencapai standar efesiensi yang diharuskan oleh direktorat jendral pengairan, departemen pekerjaan umum yang dipersyaratkan dalam standar perencanaan irigasi KP-01.

\subsection{Saran}

Dari pembahasan yang telah dilakukan pada bagian sebelumnya, maka saran yang dapat dikemukakan untuk mengatasi masalah kebutuhan air irigasi untuk daerah Mawa yaitu: (1). Sehubungan dengan ketersediaan air irigasi di saluran sekunder mawa, diharapkan kepada petani dan pemerintah bersinergi dalam membangun dan memperbaiki saluran air secara permanen agar dapat mencegah perpecahan air disaluran irigasi guna terpenuhinya kebutuhan air pada pengelolaan lahan pertanian padi sawah dan aliran air berjalan dengan lancar dan efisien. (2). Diperlukannnya pengelolaan irigasi yang lebih serius seperti menjaga kelancaran saluran, membersihkan saluran atau bergotong royong dan tetap menjaga kebersihan saluran irigasi dari sampah agar kelancaran debit air yang mengalir untuk pengelolaan pertanian dapat terwujud.

\section{DAFTAR PUSTAKA}

Asdak, C. 2010. Hidrologi dan Pengelolaan Daerah Aliran Sungai. Yogyakarta: Gadjah Mada University Press.

Fisu AA. (2016). Potensi Demand Terhadap pengembangan Kanal Jongaya \& Panampu Sebagai Moda Transportasi (Waterway) di Kota Makassar. Jurnal Manajemen Transportasi\& Logistik 3(3). 285 - 298.

Hariyanto. 2018. Analisis Penerapan Sistem Irigasi Untuk Peningkatan Hasil Pertanian di Kecamatan Cepu Kabupaten Blora. Jurnal Untidar.

Kartasapoetra, A.G, dan M.M Sutedjo. 2010. Teknologi Konservasi Tanah dan Air. Rineka Cipta. Jakarta.

Sari, Andi Kartini. (2018). Optimalisasi Saluran Pembuang To'Pongo Desa To'Pongo Kecamatan Lamasi. PENA TEKNIK: Jurnal Ilmiah Ilmu-ilmu Teknik 3(2). 117 - 126

Sari, Andi Kartini. (2019). Analisis Kebutuhan Air Irigasi untuk Lahan Persawahan Dusun To;Pongo Desa Awo Gading Kecamatan Lamasi. PENA TEKNIK: Jurnal Ilmiah Ilmu-ilmu Teknik 4(1). 47 - 51

Suppa, Rinto. (2018). Uji Sifat Fisis Air pada Alat Filtrasi Sederhana Skala Kecil untuk Pembersih Air dalam Keadaan Darurat. PENA TEKNIK: Jurnal Ilmiah Ilmu-ilmu Teknik 3(1). 37 - 46

Turu, Musyafir (2016). Analisa Keseimbangan Air pada Daerah Irigasi Salobunne Kabupaten Soppeng. PENA TEKNIK: Jurnal Ilmiah Ilmu-ilmu Teknik.1(1). 13 - 18. 